\section{Original Communications}

The Structure of a New Dipeptide from the Mushroom Clitocybe acromelalga

K. Yamano and H. Shirahama

Disproportionating Transglycosylase (D-Enzyme) in Green Algae and Cyanobacteria. Partial Purification and Characterization

B. Fuchs, P. Suttner, S. Sterner, R. WastlHUBER and E. LOOS

163

Changes in Levels of $\alpha$-Tocopherol and Ascorbate in Spruce Needles at Three Low Mountain Sites Exposed to $\mathrm{Mg}^{2+}$-Deficiency and Ozone

U. SCHMIEDEN and A. WILD

Free, Conjugated and Bound Polyamines during the Cell Cycle in Synchronized Cultures of Scenedesmus obliquus

K. Kotzabasis and H. Senger

181

Photoautotrophic Chenopodium rubrum Cell Suspension Cultures Resistant against Photosynthesis-Inhibiting Herbicides. I. Selection and Characterization

J. THIEMANN and W. BARZ

186

Differential Expression of Chitinase and $\beta-1,3-$ Glucanase Genes in Various Tissues of Potato Plants

F. Garcia-Garcia, E. Schmelzer, K. HahlBROCK, and R. ROXBY

7-Chloro-4-nitrobenzofurazan Inactivates Chloroplast $\mathrm{H}^{+}$-ATPase by Modification of Different Tyrosines, Depending on the Presence of ATP

S. BICKEL-SANDKÖTTER and K. ESSER

204

Is There an Alternative Pathway for Starch Biosynthesis in Cereal Seeds?

P. VILlAND and L. A. KLECZKowsKI

215

The Molar Mass of an Active Photosystem I Complex from the Cyanobacterium Synechococcus PCC 7002

C. Tziatzios, P. Schuck, D. Schubert and G. TSIOTIS

220

Elastosis and Cancer

W. LohmanN, W.-B. Schill, D. Bucher, Th. Peters, M. Nilles, A. SChulz and R. Bohle
Tawny Owl (Strix aluco) and Hume's Tawny Owl (Strix butleri) Are Distinct Species: Evidence from Nucleotide Sequences of the Cytochrome $b$ Gene

P. HEIDRICH and M. WINK

230

Influence of Anti-Inflammatory Flavonoids on Degranulation and Arachidonic Acid Release in Rat Neutrophils

M. Tordera, M. L. Ferrándiz and M. J. AlCARAZ

235

Directed Cell Movement in Pulsed Electric Fields

K. Franke and H. Gruler 241

Molecular Mobility of the Water Molecules in Aqueous Sucrose Solutions, Studied by ${ }^{2} \mathrm{H}-\mathrm{NMR}$ Relaxation

D. GrRLICH and H.-D. LüdEMANN 250

$c, T$-Dependence of the Self Diffusion in Concentrated Aqueous Sucrose Solutions

D. Girlich, H.-D. LüdemanN, C. Buttersack and K. BUCHHOLZ 258

\section{Notes}

The Biflavonoid Pattern of Selaginella selaginoides J. A. López-SÁez, M. J. Pérez-Alonso and A. V. Negueruela

265

Biflavonoids of Selaginella denticulata Growing in Spain

J. A. López-Sáez, M. J. Pérez-Alonso and A. V. Negueruela

267

Anthocleistol, a New Secoiridoid from Anthocleista nobilis

I. I. Madubunyi, K. P. Adam and H. Becker

Glassy State in Plant Cuticles during Growth

P. LuQue and A. Heredia

Pheromones. The Sex Pheromone Complex of the Female Arctiid Moth Thyria jacobaeae (Lepidoptera, Arctiidae) (In German)

H. J. Bestmann, E. JansSEN, F. KeRn, D. SChäFER and O. VOSTROWSKY

276 


\title{
Reconstitution of an Allophycocyanin Trimer Complex Containing the C-Terminal 21-23 kDa Domain of the Core-Membrane Linker Polypeptide $\mathrm{L}_{\mathrm{cm}}$
}

\author{
Lothar Gottschalk ${ }^{\mathrm{a}}$, Friedrich Lottspeich ${ }^{\mathrm{b}}$ and Hugo Scheer ${ }^{\mathrm{a}}$ \\ a Botanisches Institut der Universität, Menzinger Straße 67, D-80638 München, \\ Bundesrepublik Deutschland \\ b Max-Planck-Institut für Biochemie, Am Klopferspitz, D-82152 Martinsried, \\ Bundesrepublik Deutschland
}

Z. Naturforsch. 49c, 331-336 (1994); received February 18, 1994

Allophycocyanin, Linker, Anchor Protein, Phycobilisome Core, Mastigocladus laminosus

Allophycocyanin (AP) was isolated from extracts of the cyanobacterium Mastigocladus laminosus. A fraction enriched in AP-associated polypeptides with apparent molecular masses of $21-23 \mathrm{kDa}$ in SDS-PAGE, was isolated on a preparative scale and identified as a homologous mixture of C-terminal fragments of the core-membrane linker polypeptide $\mathrm{L}_{\mathrm{cm}}$. The complex $\left(\alpha^{\mathrm{AP}} \beta^{\mathrm{AP}}\right)_{3} \cdot 21-23 \mathrm{kDa}$ was reconstituted and characterized by sucrose density gradient ultracentrifugation, absorption, fluorescence emission and circular dichroism spectroscopy. The 21-23 kDa polypeptides were found to induce spectral changes in AP similar to those induced by the small core linker polypeptide $\mathrm{L}_{c}{ }^{8.9}$. Possible functions of the complex in phycobilisomes are discussed.

\section{Introduction}

Phycobilisomes, the light-harvesting antennae of cyanobacteria, red algae and cyanelles, are supramolecular, highly-structured protein complexes located on the thylakoid surface (Wehrmeyer, 1983; Gantt, 1986). They are composed of chromophore-bearing phycobiliproteins (Scheer, 1982; Glazer, 1985; MacColl and Guard-Friar, 1987) absorbing light over a wide spectral range, and of linker polypeptides which regulate and stabilize the phycobilisome structure, but also modify the light-absorption properties of the phycobiliproteins (Tandeau de Marsac and Cohen-Bazire, 1977; Bryant, 1991).

\footnotetext{
Abbreviations: PC, phycocyanin; PEC, phycoerythrocyanin; AP, allophycocyanin; APB, allophycocyanin B; $\alpha$, $\beta$, biliprotein subunits; $L$, linker polypeptide, subscripts denoting origin and function in phycobilisomes ( $r$, rod; c, core; rc, rod core; $\mathrm{cm}$, core membrane), superscripts denoting molecular weight in $\mathrm{kDa}$; OD, optical density; $\mathrm{OD} \cdot \mathrm{ml}$, unit of protein quantity, OD multiplied by sample volume in $\mathrm{ml}$, subscripts denoting wavelength in $\mathrm{nm}$; SDS-PAGE, sodium dodecylsulfate-polyacrylamide-gelelectrophoresis; $\mathrm{CD}$, circular dichroism; $\mathrm{p} / \mathrm{s}$, peak $\left(\lambda_{\max }\right)$ to-shoulder $(600 \mathrm{~nm})$ absorbance ratio; $\Delta A / A_{\max }$, ratio of CD signal intensity to absorbance value at $\lambda_{\max }$.

0939-5075/94/0500-0331 \$03.00

(C) Verlag der Zeitschrift für Naturforschung,

D-72072 Tübingen
}

In hemidiscoidal phycobilisomes, an array of rods is linked by one or more rod-core linker polypeptides to the phycobilisome core. The bi- or tricylindrical core substructures are formed by allophycocyanin (AP), two minor biliproteins structurally related to AP, and the two linkers $L_{c}$ and $\mathrm{L}_{\mathrm{cm}}$. The latter, a large polypeptide of $127 \mathrm{kDa}$ molecular mass in the cyanobacterium Mastigocladus laminosus (Esteban, 1993), contains several internal repeats and plays a singular role. It anchors the core to the membrane (Redlinger and Gantt, 1982; Rusckowski and Zilinskas, 1982; Reuter and Wehrmeyer, 1990), and is involved in the organization of the core, but also carries a chromophore which is probably the terminal emitter to photosystem II (Gindt et al., 1992; Zhao et al., 1992).

The key role of the linker polypeptides in the aggregate formation and the fine-tuning of the absorption characteristics of the phycobiliproteins has been widely studied, but is still only poorly understood. A technique for the isolation of linker polypeptides and their fragments and for the reconstitution to biliprotein-linker complexes recently developed in our laboratory (Gottschalk et al., 1991 and 1993), has facilitated the study of these proteins. Here, we present results on a complex of AP-trimer with C-terminal fragments of the $\mathrm{L}_{\mathrm{cm}}$ polypeptide, which shows a strong hyper- 
chromism as compared to AP-trimers without linker. Our findings may be significant in the present discussion of the phycobilisome architecture of this organism.

\section{Materials and Methods}

Absorption and $C D$ measurements were made at an optical density of $0.5-0.75$. Fluorescence emission was measured at an optical density of 0.1 at the absorption maximum in $1 \mathrm{~cm}$ cells; excitation was at $580 \mathrm{~nm}$. Allophycocyanin was isolated from Mastigocladus laminosus on DE 52 (Whatman), pre-purified on hydroxylapatite Bio-Gel HT (BioRad), and purified on Fractogel TSK DEAE650(2) (Merck) from all contaminations of other biliproteins and of linker polypeptides by the methods previously described (Gottschalk et al., 1991 and 1993; Gottschalk, 1993). 21-23 kDa polypeptides were isolated with buffers containing $3.5 \mathrm{M}$ urea (Serva, p.a. grade) from pre-purified AP on S-Sepharose Fast Flow (Pharmacia) as described previously for $\mathrm{L}_{\mathrm{c}}^{8.9}$ (Gottschalk et al., 1993). Reconstitution experiments $-6 \mathrm{OD}_{620} \cdot \mathrm{ml}$ AP (in $230 \mu \mathrm{l} 30 \mathrm{~mm}$ potassium phosphate buffer, $\mathrm{pH} 7$, containing $3.5 \mathrm{M}$ urea) and $1.2 \mathrm{OD}_{276} \cdot \mathrm{ml}$ enriched fraction of $21-23 \mathrm{kDa}$ polypeptides (in $400 \mu \mathrm{l} 10 \mathrm{~mm}$ Tris $/ \mathrm{HCl}, \mathrm{pH} 8.9$, containing $3.5 \mathrm{M}$ urea and $100 \mathrm{~mm} \mathrm{KCl}$ ) were mixed, reconstituted in potassium phosphate buffer (700 mM, pH 7.5), purified by sucrose density gradient ultracentrifugation and characterized by methods described previously for complexes containing $\mathrm{L}_{\mathrm{c}}^{8.9}$ (Gottschalk et al., 1993). The aggregation state was determined by $3-12 \%$ sucrose density gradient ultracentrifugation in $700 \mathrm{~mm}$ potassium phosphate buffer ( $\mathrm{pH} 7.5)$ as described previously (Gottschalk et al., 1993). Amino acid sequences LysC digestion of protein bands in polyacrylamide matrix was followed by elution and HPLC separation of the fragments (Eckerskorn and Lottspeich, 1989). N-terminal sequences of the fragments were determined as described previously (Eckerskorn et al., 1988; Lottspeich, 1985). SDS-PAGE was done according to Lämmli (1970), using a 5\% stacking gel and a $15 \%$ separation gel.

\section{Results}

In a previous publication, a new method for the isolation and purification of biliproteins and link- er polypeptides and for reconstitution of biliprotein-linker complexes has been introduced and applied to the reconstitution of $\left(\alpha^{\mathrm{AP}} \beta^{\mathrm{AP}}\right)_{3}$ and of $\left(\alpha^{\mathrm{AP}} \beta^{\mathrm{AP}}\right)_{3} \cdot \mathrm{L}_{\mathrm{c}}^{8.9}$ (Gottschalk et al., 1993). During this work, another reconstituted complex, $\left(\alpha^{\mathrm{AP}} \beta^{\mathrm{AP}}\right)_{3} \cdot 21-23 \mathrm{kDa}$, had been prepared (Gottschalk et al., 1993), but could not be further characterized then because the three $21-23 \mathrm{kDa}$ polypeptides were $\mathrm{N}$-terminally blocked. The related polypeptides were now enriched by chromatography on S-Sepharose FF. The fraction of $21-23 \mathrm{kDa}$ polypeptides eluting at about $100 \mathrm{~mm}$ $\mathrm{KCl}$ was still contaminated by other polypeptides (Fig. 1, lane 1). However, the major three bands at apparent molecular masses of $21-23 \mathrm{kDa}$ were the only ones in this fraction reconstituting stable complexes with AP (Fig. 1, lane 3), whereas the contaminations precipitated and were lost during the reconstitution and subsequent purification procedure. Therefore, under circumstances favouring specific interactions, reconstitution can be used to obtain pure and specific complexes from impure samples. The polypeptides of the three bands forming a complex with AP were separately cleaved with $\mathrm{LysC}$, and some of the fragments were sequenced (Table I). All bands contain cleavage products identified as fragments of the C-terminal part of $\mathrm{L}_{\mathrm{cm}}$, by comparison with the

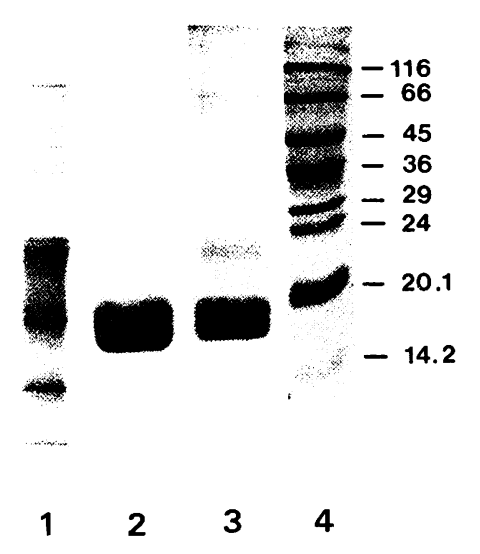

Fig. 1. SDS-PAGE of isolated polypeptides and reconstituted complexes. Lane 1: fraction of $21-23 \mathrm{kDa}$ polypeptides isolated from S-Sepharose FF column. Lane 2: $\left(\alpha^{\mathrm{AP}} \beta^{\mathrm{AP}}\right)_{3}$ complex reconstituted as a control. Lane 3: reconstituted $\left(\alpha^{\mathrm{AP}} \beta^{\mathrm{AP}}\right)_{3} \cdot 21-23 \mathrm{kDa}$ complex. Lane $4:$ molecular weight markers $(14.2,20.1,24,29,36,45,66$ and $116 \mathrm{kDa})$. 
Table I. Sequences of LysC fragments of the upper, middle and lower band of $21-23 \mathrm{kDa}$ polypeptides in the reconstituted complex with AP (Fig. 1, lane 3), and amino acid positions of identical sequences of $\mathrm{L}_{\mathrm{cm}}$ from Mastigocladus laminosus (Esteban, 1993).

\begin{tabular}{lll}
\hline Band & Sequences & Position \\
\hline upper & LLADGGLK & $1063-1070$ \\
& AAADLVK & $1110-1116$ \\
middle & FYTPYPNTK & $1029-1037$ \\
& LLADGGLK & $1063-1070$ \\
lower & FYTPYPNTK & $1029-1037$ \\
& LLADGGLK & $1063-1070$ \\
& AAVEAMVNSP & $1071-1080$ \\
\hline
\end{tabular}

amino acid sequence deduced from the DNA sequence (Esteban, 1993).

Esteban (1993) has recently also identified a $23 \mathrm{kDa}$ polypeptide as a C-terminal fragment of $\mathrm{L}_{\mathrm{cm}}$ starting at amino acid position 923 . The similar size and sequence overlaps show that our polypeptides are closely related to the latter. Since they are $\mathrm{N}$-terminally blocked, it could not be determined whether they differ from each other $\mathrm{N}$ - or $\mathrm{C}$-terminally. The finding of this family of closely related $\mathrm{L}_{\mathrm{cm}}$ fragments can be rationalized by an attack of an endogenous protease or $M$. laminosus on regions of $\mathrm{L}_{\mathrm{cm}}$ not protected inside an AP trimer after subjecting phycobilisomes to dissociating conditions. $21-23 \mathrm{kDa}$ seems to be a common size for stable fragments of linker polypeptides protected inside biliprotein trimers against further degradation ( $\mathrm{Yu}$ and Glazer, 1982; Lundell et al., 1981; Lundell and Glazer, $1983 \mathrm{a}$; Gottschalk et al., 1991; Glauser et al., 1992 b); we suggest that the C-terminal domain of $\mathrm{L}_{\mathrm{cm}}$ is following the same principle.

The basis for the N-terminal block of our isolates is unclear. N-terminally blocked linker polypeptides have been reported from other organisms (Lundell et al., 1981; Glauser, 1991; Glauser et al., 1992 b), but are not expected for proteolytic fragments. A block could be due to reaction with cyanate ions in the $3.5 \mathrm{M}$ urea solution used throughout the isolation, although no such effect has been observed previously in our work with biliproteins and linker polypeptides of $M$. laminosus isolated under similar conditions (Gottschalk et al., 1991 and 1993; Gottschalk, 1993).

Complete complexation of trimeric AP with the
21-23 kDa polypeptides was ensured by the use of an excess of the latter, as discussed in Gottschalk et al. (1993). The reconstituted $\left(\alpha^{\mathrm{AP}} \beta^{\mathrm{AP}}\right)_{3} \cdot 21-$ $23 \mathrm{kDa}$ complex was predominantly $(\geq 85 \%)$ trimeric; only traces of monomeric $(\leq 8 \%)$ and hexameric $(\leq 7 \%)$ aggregates could be detected by sucrose density gradient ultracentrifugation. Only the trimeric fraction from the gradient was used for the spectra shown in Fig. 2. No contamination by APB or the chromophore-bearing $\mathrm{N}$-terminus of $\mathrm{L}_{\mathrm{cm}}$ was detected by spectroscopic methods or SDS-PAGE.

The red absorption band of the reconstituted complex was at $\lambda_{\max }=651.5 \mathrm{~nm}$, and had an extremely high $\mathrm{p} / \mathrm{s}$-ratio of up to 2.95 ; the fluorescence emission was at $\lambda_{\max }=663 \mathrm{~nm}$ (Fig. $2 \mathrm{a}$ ). The complex gave very strong $C D$ signals with $\Delta A / A_{\max }=4.7 \cdot 10^{-4}$ (Fig. 2). When compared to the spectra of reconstituted $\left(\alpha^{\mathrm{AP}} \beta^{\mathrm{AP}}\right)_{3}$ and $\left(\alpha^{\mathrm{AP}} \beta^{\mathrm{AP}}\right)_{3} \cdot \mathrm{L}_{\mathrm{c}}^{8.9}$ (Gottschalk et al., 1993), the absorption and fluorescence emission maxima of the new complex are at intermediate values.

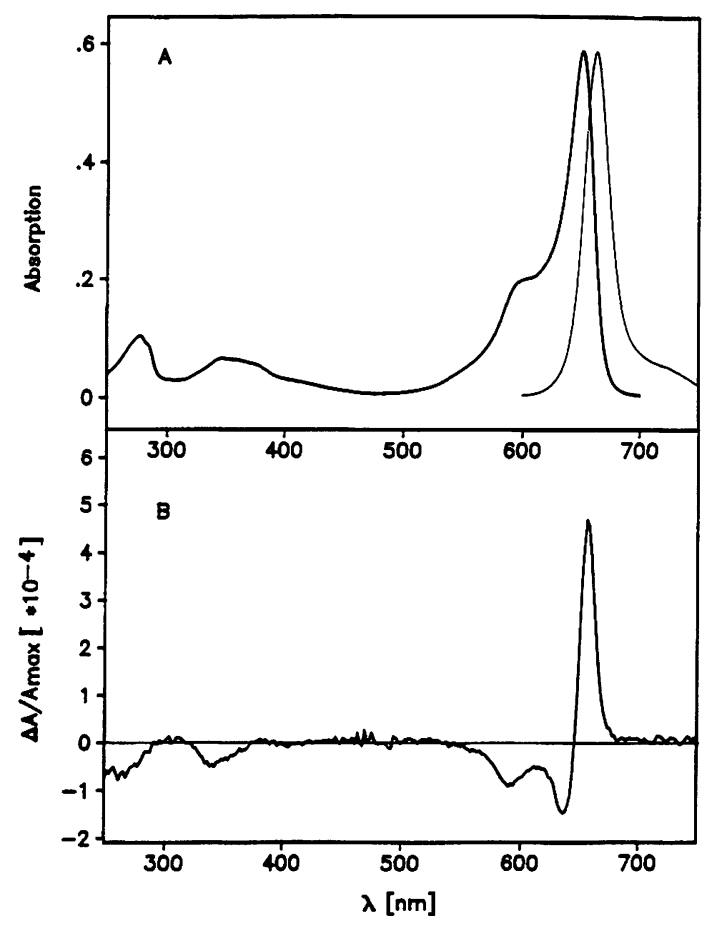

Fig. 2. Absorption (A, heavy line, left ordinate), fluorescence emission ( $\mathbf{A}$, thin line, right ordinate) and $C D$ spectra $(B)$ of the reconstituted $\left(\alpha^{\mathrm{AP}} \beta^{\mathrm{AP}}\right)_{3} \cdot 21-23 \mathrm{kDa}$ complex. 
However, $\mathrm{p} / \mathrm{s}=2.95$ is the highest value measured for any AP-complex as yet. The overall shape and the signal positions of the $C D$ spectrum are similar to $\left(\alpha^{\mathrm{AP}} \beta^{\mathrm{AP}}\right)_{3} \cdot L_{c}^{8.9}$, but the signal intensities are rather different. $\left(\alpha^{\mathrm{AP}} \beta^{\mathrm{AP}}\right)_{3} \cdot 21-23 \mathrm{kDa}$ shows the highest value of $\Delta A / A_{\max }$ for the three complexes, while the other linker-containing complex, $\left(\alpha^{\mathrm{AP}} \beta^{\mathrm{AP}}\right)_{3} \cdot \mathrm{L}_{\mathrm{c}}^{8.9}$, gives the lowest amplitudes $\left(\Delta A / A_{\max }=1.5 \cdot 10^{-4}\right.$; Gottschalk et al., 1993). In $\left(\alpha^{\mathrm{AP}} \beta^{\mathrm{AP}}\right)_{3} \cdot 21-23 \mathrm{kDa}$, the negative signal at around $635 \mathrm{~nm}$ is more pronounced than that at around $594 \mathrm{~nm}$; in $\left(\alpha^{\mathrm{AP}} \beta^{\mathrm{AP}}\right)_{3} \cdot \mathrm{L}_{\mathrm{c}}^{8.9}$, the intensities of these signals are reversed.

\section{Discussion}

$\mathrm{L}_{\mathrm{cm}}$ is the largest and most complex linker in phycobilisomes. It plays a central role in the energy transfer from the rods through the core to the photosystems. Specific interactions with the biliproteins are necessary to explain the functions of $\mathrm{L}_{\mathrm{cm}}$ as a structural protein of the core, as the anchor protein to the thylakoid membrane, as a linker modifying the spectral properties of the associated biliproteins, and as the presumed terminal emitter of the phycobilisome (Redlinger and Gantt, 1982; Rusckowski and Zilinskas, 1982; Lundell and Glazer, $1983 \mathrm{a} / \mathrm{b} / \mathrm{c}$; Houmard et al., 1990; Capuano et al., 1991; Gindt et al., 1992; Zhao et al., 1992). Complexes containing $\mathrm{L}_{\mathrm{cm}}$ have been isolated only as large core fragments containing also other linkers and biliproteins (Lundell and Glazer, 1983 a/c; Isono and Katoh, 1987; Reuter and Wehrmeyer, 1990). AP-complexes containing a single defined linker have been described only for $\mathrm{L}_{\mathrm{c}}^{8.9}$ and rod-core linkers (Lundell and Glazer, 1983 b; Füglistaller et al., 1987; Glauser et al., 1990; Gottschalk et al., 1993).

We have shown here, that the C-terminal domain of $L_{c m}$ is capable of forming specific complexes with AP trimers. This domain is not singular in $\mathrm{L}_{\mathrm{cm}}$. Following a $\mathrm{N}$-terminal biliprotein do- main, $\mathrm{L}_{\mathrm{cm}}$ polypeptides contain two to four such repeats, which are also homologous to the $\mathrm{N}$-terminal domains of rod and rod-core linkers (Bryant, 1988; Houmard et al., 1990). In phycobilisomes containing $\mathrm{L}_{\mathrm{cm}}$ with four repeats, the C-terminal domain has been suggested to link PC (Capuano et al., 1991) or AP-hexamers (Isono and Katoh, 1987; Bryant, 1991) at the basis of two of the rods to the core. This would define the C-terminus of the $\mathrm{L}_{\mathrm{cm}}$ of $M$. laminosus and Anabaena sp. PCC 7120 as a rod-core linker, and would have to be taken into account with regard to the proposed stoichiometries of these polypeptides (Glauser et al., 1992a). Rods with AP at their base would either require the interaction of $\mathrm{L}_{r}{ }^{34.5}$, PC with AP, binding the outer PC-hexamers to the basal AP-disc. Alternatively, one of the presumed rodcore linkers would have to play this role, being in reality a misnamed rod linker. In this context it is interesting that an $(\alpha \beta)_{6}{ }^{\mathrm{PC}} \cdot \mathrm{L}_{\mathrm{rc}}{ }^{29.5} \cdot(\alpha \beta)_{3}{ }^{\mathrm{AP}} \cdot \mathrm{L}_{\mathrm{c}}{ }^{8.9}$ complex of unknown morphology and location within the phycobilisome has been isolated and reconstituted by Glauser et al. (1993). This so-called rod-core complex could then also be part of a special rod type.

It should be pointed out, however, that the experimental evidence supporting this specific phycobilisome model (Bryant et al., 1991; Glauser et al., 1992a/b; Esteban, 1993) is still ambiguous. Our results are also compatible with other models: the complex containing the C-terminal domain of $\mathrm{L}_{\mathrm{cm}}$ could be involved in the interaction between neighbouring phycobilisomes, and it could also be an integral part of the core.

\section{Acknowledgements}

This work was supported by the Deutsche Forschungsgemeinschaft, Bonn (Sonderforschungsbereich 143, project A 1). The authors wish to thank A. Esteban and W. Sidler (ETH Zürich) for making available important data prior to publica. tion. 
Bryant D. A. (1988), Genetic analysis of phycobilisome biosynthesis, assembly, structure, and function in the cyanobacterium Synechococcus sp. PCC 7002. In: Light-energy transduction in photosynthesis: Higher plant and bacterial models (S. E. Stevens Jr. and D. A. Bryant, eds.). American Society of Plant Physiologists, Rockville, MD, 62-90.

Bryant D. A. (1991), Cyanobacterial phycobilisomes: Progress towards a complete structural and functional analysis via molecular genetics. In: Cell culture and somatic cell genetics of plants, Vol. 7 B: The molecular biology of plastids and mitochondria (L. Bogorad and I. K. Vasil, eds.). Academic Press Inc., New York, 255-298.

Bryant D. A., Stirewalt V. L., Glauser M., Frank G., Sidler W. and Zuber H (1991), A small multigene family encodes the rod-core linker polypeptides of Anabaena sp. PCC 7120 phycobilisomes. Gene 107, 91-99.

Capuano V., Braux A.-S., Tandeau de Marsac N. and Houmard J. (1991), The "anchor polypeptide" of cyanobacterial phycobilisomes. Molecular characterization of the Synechococcus sp. PCC 6301 apce gene. J. Biol. Chem. 266, 7239-7247.

Eckerskorn C. and Lottspeich F. (1989), Internal amino acid sequence analysis of proteins separated by gel electrophoresis after tryptic digestion in polyacrylamide matrix. Chromatographia 29, 92-94.

Eckerskorn C., Mewes W., Goretzki H. and Lottspeich F. (1988), A new siliconized-glass fiber as support for protein-chemical analysis of electroblotted proteins. Eur. J. Biochem. 176, 509-519.

Esteban A. M. (1993), Sequenzierung, Klonierung und Charakterisierung der Gene von Core-Polypeptiden aus dem Cyanobakterium Mastigocladus laminosus. Dissertation, Eidgenössische Technische Hochschule Zürich.

Füglistaller P., Mimuro M., Suter F. and Zuber H. (1987), Allophycocyanin complexes of the phycobilisome from Mastigocladus laminosus. Influence of the linker polypeptide $L_{c}^{8.9}$ on the spectral properties of the phycobiliprotein subunits. Biol. Chem. HoppeSeyler 368, 353-367.

Gantt E. (1986), Phycobilisomes. In: Encyclopedia of plant physiology, New series, Vol. 19, Photosynthesis III (L. A. Staehelin and C. J. Arntzen, eds.). Springer Verlag, Berlin, Heidelberg, New York, Tokio, 260268.

Gindt Y. M., Zhou J., Bryant D. A. and Sauer K. (1992), Core mutations of Synechococcus sp. PCC 7002 phycobilisomes: A spectroscopic study. J. Photochem. Photobiol. B: Biol. 15, 75-89.

Glauser M. (1991), Studies on the structure and function of cyanobacterial phycobilisomes: Genetic and protein-chemical characterization of linker polypeptides in the phycobilisomes of Mastigocladus laminosus and Anabaena sp. PCC 7120. Dissertation, Eidgenössische Technische Hochschule Zürich.

Glauser M., Sidler W., Frank G. and Zuber H. (1990), Studies on the rod-substructure of the phycobilisome from the cyanobacterium Mastigocladus laminosus. In: Current Research in Photosynthesis, Vol. II (M. Baltscheffsky, ed.). Kluver Academic Publishers, Dordrecht, Boston, London, 89-92.

Glauser M., Bryant D. A., Frank G., Wehrli E., Rusconi
S. S., Sidler W. and Zuber H. (1992a), Phycobilisome structure in the cyanobacteria Mastigocladus laminosus and Anabaena sp. PCC 7120. Eur. J. Biochem. 205, 907-915.

Glauser M., Stirewalt V. L., Bryant D. A., Sidler W. and Zuber H. (1992 b), Structure of the genes encoding the rod-core linker polypeptides of Mastigocladus laminosus phycobilisomes and functional aspects of the phycobiliprotein/linker-polypeptide interactions. Eur. J. Biochem. 205, 927-937.

Glauser M., Sidler W. and Zuber H. (1993), Isolation, characterization and reconstitution of phycobiliprotein rod-core linker polypeptide complexes from the phycobilisome of Mastigocladus laminosus. Photochem. Photobiol. 57, 344-351.

Glazer A. N. (1985), Light harvesting by phycobilisomes. Ann. Rev. Biophys. Chem. 14, 47-77.

Gottschalk L. (1993), Isolierung von Linker-Polypeptiden und Rekonstitution von Biliprotein-Linker-Komplexen aus Mastigocladus laminosus. Dissertation, Ludwig-Maximilian-Universität München.

Gottschalk L., Fischer R., Lottspeich F. and Scheer H. (1991), Origin of the red-shifted absorption in phycocyanin 632 from Mastigocladus laminosus. Photochem. Photobiol. 54, 2, 283-288.

Gottschalk L., Lottspeich F. and Scheer H. (1993), Reconstitution of allophycocyanin from Mastigocladus laminosus with isolated linker polypeptide. Photochem. Photobiol. 58, 761-767.

Houmard J., Capuano V., Colombano M. V., Coursin T. and Tandeau de Marsac N. (1990), Molecular characterization of the terminal energy acceptor of cyanobacterial phycobilisomes. Proc. Natl. Acad. Sci. U.S.A. 87, 2152-2156.

Isono T. and Katoh T. (1987), Subparticles of Anabaena phycobilisomes. II. Molecular assembly of allophycocyanin cores in reference to "anchor" protein. Arch. Biochem. Biophys. 256, 317-324.

Lämmli U. K. (1970), Cleavage of structural proteins during the assembly of the head of bacteriophage T 4 . Nature 227, 680-685.

Lottspeich F. (1985), Microscale isocratic separation of phenylthiohydantoin amino acid derivatives. J. Chromatogr. 326, 321-327.

Lundell D. J. and Glazer A. N. (1983a), Molecular architecture of a light-harvesting antenna - Structure of the $18 \mathrm{~S}$ core-rod subassembly of the Synechococcus 6301 phycobilisome. J. Biol. Chem. 258, 894-901.

Lundell D. J. and Glazer A. N. (1983 b), Molecular architecture of a light-harvesting antenna - Core substructure in Synechococcus 6301 phycobilisomes: Two new allophycocyanin and allophycocyanin B complexes. J. Biol. Chem. 258, 902-908.

Lundell D. J. and Glazer A. N. (1983c), Molecular architecture of a light-harvesting antenna - Quaternary interactions in the Synechococcus 6301 phycobilisome core as revealed by partial tryptic digestion and circular dichroism studies. J. Biol. Chem. 258, 8708-8713.

Lundell D. J., Williams R. C. and Glazer A. N. (1981), Molecular architecture of a light-harvesting antenna. In vitro assembly of the rod substructures of Synechococcus 6301 phycobilisomes. J. Biol. Chem. 256, 3580-3592. 
MacColl R. and Guard-Friar D. (1987), Phycobiliproteins. CRC Press, Boca Raton.

Redlinger T. and Gantt E. (1982), A M 95,000 polypeptide in Porphyridium cruentum phycobilisomes and thylakoids: Possible function in linkage of phycobilisomes to thylakoids and in energy transfer. Proc. Natl. Acad. Sci. U.S.A. 79, 5542-5546.

Reuter W. and Wehrmeyer W. (1990), Core substructure in Mastigocladus laminosus phycobilisomes. II. The central part of the tricylindrical core - $\mathrm{AP}_{\mathrm{CM}}-$ contains the "anchor" polypeptide and no allophycocyanin B. Arch. Microbiol. 153, 111-117.

Rusckowski M. and Zilinskas B. A. (1982), Allophycocyanin I and the 95 kilodalton polypeptide. The bridge between phycobilisomes and membranes. Plant Physiol. 70, 1055-1059.

Scheer H. (1982), Phycobiliproteins: Molecular aspects of photosynthetic antenna systems. In: Light reaction path of photosynthesis (F. K. Fong, ed.). Springer Verlag, Berlin, 7-45.

Tandeau de Marsac N. and Cohen-Bazire G. (1977), Molecular composition of bacterial phycobilisomes.

Proc. Natl. Acad. Sci. U.S.A. 74, 1635-1639.

Wehrmeyer W. (1983), Organization and composition of cyanobacterial and rhodophycean phycobilisomes. In: Photosynthetic procaryotes: Cell differentiation and function (G. C. Papageorgiu and L. Packer, eds.). Elsevier Science Publishing Co. Inc., Amsterdam, $1-22$.

Yu M.-H. and Glazer A. N. (1982), Cyanobacterial phycobilisomes. Role of the linker polypeptides in the assembly of phycocyanin. J. Biol. Chem. 257, 34293433.

Zhao J., Zhou J. and Bryant D. A. (1992), Energy transfer processes in phycobilisomes as deduced from mutational analyses. Photosynth. Res. 34, 83. 